\title{
The Effect of Si/Al on Mechanical Properties and Fracture Behavior of Stainless Steel Mesh/Cr Reinforced Geopolymer Composites
}

\author{
Jingkun Yuan ${ }^{1, *}$, Peigang $\mathrm{He}^{1}$, and Dechang Jia ${ }^{1}$ \\ ${ }^{1}$ School of Materials Science and Engineering, Harbin Institute of Technology, P. O. Box 433 Harbin \\ 150001, P. R. China
}

\begin{abstract}
In this study, a series stainless steel $\mathrm{mesh} / \mathrm{Cr}_{\mathrm{p}}$ reinforced geopolymer composites with different $\mathrm{Si} / \mathrm{Al}$ molar ratio $(\boldsymbol{N})$ were designed and prepared, where $N=1.75,2$ and 2.25 , respectively. The effect of $\mathrm{Si} / \mathrm{Al}$ molar ratio in the geopolymer matrix on mechanical properties and fracture behavior of the geopolymer composites were investigated. The microstructure of geopolymer became more compact when $\mathrm{Si} / \mathrm{Al}$ increased from 1.75 to 2 , which was beneficial to the improvement of geopolymer's mechanical properties. And continuing to rise to 2.25 for $\mathrm{Si} / \mathrm{Al}$, the completely curing of geopolymer composites required more time compared with lower $\mathrm{Si} / \mathrm{Al}$, which can be attributed to the different microstructure and chemical composition caused by the different $\mathrm{Si} / \mathrm{Al}$. The optimum $\mathrm{Si} / \mathrm{Al}$ molar ratio was about 2 at which the composites samples present the best mechanical properties with the flexure strength of $115.3 \mathrm{MPa}$ and elastic modulus of $11.0 \mathrm{GPa}$, respectively. The results of fracture behavior suggested that geopolymer composites with $N$ is 2.25 displayed the behavior characteristics of metal materials, which can be attributed to a poor integrated condition in interface between reinforcements and geopolymer matrix.
\end{abstract}

\section{Introduction}

While traditional design and evaluation approaches are based on the principle of maximizing the economic efficiency and include quality, cost, and time, the new approach of 'sustainable construction' emphasizes the importance of reducing the environmental impact of buildings and infra-structures [1]. Therefore, the reduction of $\mathrm{CO}_{2}$ emissions and energy consumption in the cement industry has recently become a contentious issue, which corresponds to approximately $7 \%$ of the total emissions into the earth's atmosphere. In an effort to limit the environmental impact of concrete materials, there is increasing interest in the development an

environmental-friendly material. As an outstanding candidate, geopolymer can provide comparable performance to traditional cementitious binders in a range of applications, but with the added advantage of significantly reduced greenhouse emissions [2-7].

\footnotetext{
* Corresponding author: yuanjingkun@126.com
} 
Geopolymers are a class of cementitious aluminosilicate binder materials synthesized by a geopolymerization reaction between alumino-silicate oxides and alkali-metal silicate solutions under alkaline conditions, with partially or fully amorphous polymeric structures containing tetrahedral $\mathrm{SiO}_{4}$ and $\mathrm{AlO}_{4}$ randomly distributed along the polymeric chains [8-11]. The researches on the geopolymerization mechanism in this system are attracting more and more attentions, and the process may be summarized briefly as follows: dissolution, rearrangement, condensation and re-solidification [12-18]. The structure and mechanical properties of geopolymers are affected by several parameters such as chemical composition and reactivity of the raw materials, nature and concentration of the activating solution, curing conditions. The $\mathrm{Si} / \mathrm{Al}$ molar ratio has a significant effect on the structural and mechanical performance. An optimum $\mathrm{Si} / \mathrm{Al}$ ratio increases the strength of the resulting geopolymer. Apart from the ideal ratio, some losses may occur in the mechanical properties of the material due to the change of the geopolymer structure [19].

In this paper, a series stainless steel mesh/Cr $r_{p}$ reinforced geopolymer composites with different Si/Al molar ratio $(N)$ were designed and prepared, where $N=1.75,2$ and 2.25, respectively. The effect of $\mathrm{Si} / \mathrm{Al}$ molar ratio in the geopolymer matrix on mechanical properties and fracture behavior of the geopolymer composites were investigated.

\section{Experiments}

\subsection{Material and synthesis}

Geopolymers resin with composition of $\mathrm{Si} / \mathrm{Al}=N, 1.75,2$ and 2.25 , respectively, were obtained by mixing metakaolin powder with potassium silicate solution. The metakaolin was prepared by calcining kaolin at $800^{\circ} \mathrm{C}$ for $2 \mathrm{~h}$ and the potassium silicate solution was prepared by dissolving a certain amount of amorphous silica (Shanghai Dixiang Indus, China) into $\mathrm{KOH}$ (Tianjin Fuchen Indus., China) solution stirring for $48 \mathrm{~h}$ in order to dissolve the silica completely. Then the metakaolin powder and chromium powder ( $40 \%$ mass ratio of metakaolin) were gradually added into the potassium silicate solution under ultrasonic-assisted high-shear mixer. To prepare composite samples, seven stainless steel mesh layers $(\varnothing 70 \mathrm{~mm}$ ) were impregnated with the geopolymer resin and laid on top of each other. The lamination structure was formed by vacuum-bag technique and pressed at $\sim 3 \mathrm{MPa}$ for $1 \mathrm{~h}$, followed by curing $3 \mathrm{~d}$ at $60^{\circ} \mathrm{C}$. After demoulding the hardened geopolymer composites were further cured at the same temperature for another $2 \mathrm{~d}$. The major ingredient of the stainless steel mesh is $\mathrm{Cr}_{0.19} \mathrm{Fe}_{0.7} \mathrm{Ni}_{0.11}$. The $\mathrm{Si} / \mathrm{Al}$ molar ratio was adjusted by adding extra amorphous silica, and the amount of amorphous silica was calculated according to the $\mathrm{Si} / \mathrm{Al}$ ratio.

\subsection{Characterization}

The phases of geopolymer composites were characterized using an X-ray diffractometer (XRD: Rigaku, D/MAX-2200VPC, Tokyo, Japan) with CuKa radiation at a scan rate of 4 $\%$ min. Flexural strength measurements were conducted on specimens $(4 \mathrm{~mm} \times 3 \mathrm{~mm} \times 36 \mathrm{~mm}$ ) using a three-point-bending fixture on an Instron-500 testing machine with a span length of $30 \mathrm{~mm}$ at a crosshead speed of $0.5 \mathrm{~mm} / \mathrm{min}$. Tensile strength measurements were carried out on a Work of fracture was calculated by the area between load curves and X axis in the load/displacement curves till the load dropped to $90 \%$ of the maximum load. Six specimens were tested under each test condition. Fracture morphology of the geopolymer composites were investigated by a scanning electron microscope (SEM, $30 \mathrm{KV}$, Quanta $200 \mathrm{FEG}$, FEI Co., USA). 


\section{Results and discussion}

\subsection{Phase composition}

Fig. 1 provided XRD patterns of geopolymer composites with different $\mathrm{Si} / \mathrm{Al}$ ratio. As can be seen, all the samples show typical amorphous character, i.e., a broad amorphous hump at $\sim 28^{\circ} 2 \theta$ [20], which suggested that the different $\mathrm{Si} / \mathrm{Al}$ ratio did not changed the nature of the geopolymer matrix. With the rise of $\mathrm{Si} / \mathrm{Al}$, the amount of $\mathrm{SiO}_{2}$ in the composites decreased gradually. The results of XRD also indicated that the stainless steel mesh and chromium powder were not involved in the reaction with geopolymer matrix [21].

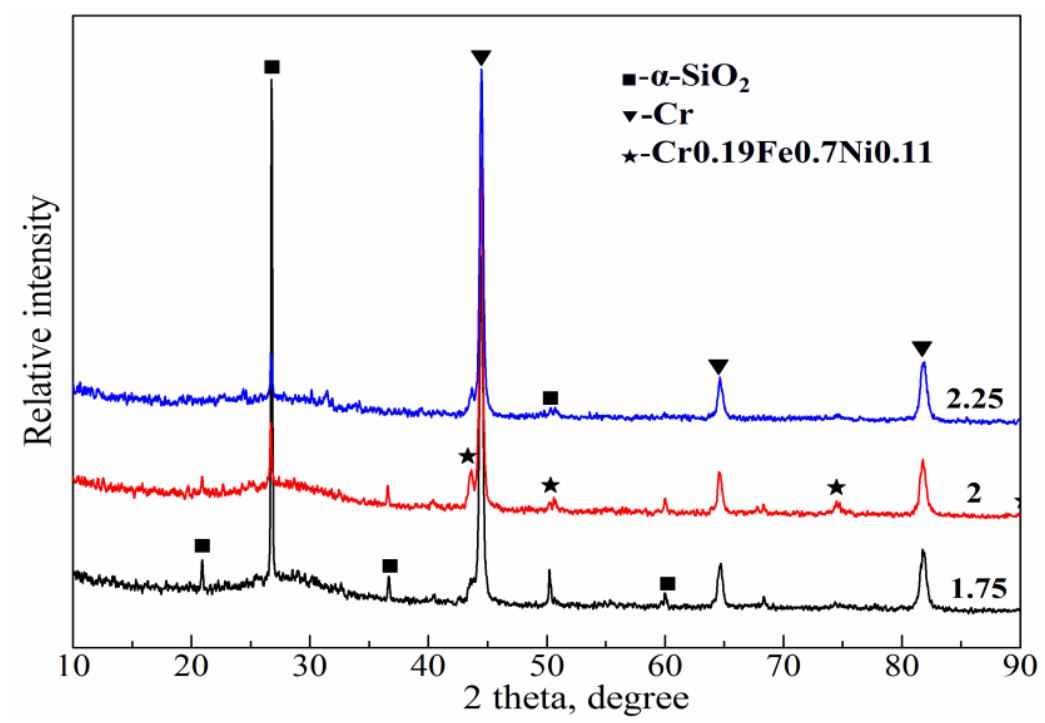

Fig. 1. XRD patterns of geopolymer composites with different $\mathrm{Si} / \mathrm{Al}$ ratio.

\subsection{Microstructure}

Fig. 2 displayed the surface morphologies of geopolymer composites with different $\mathrm{Si} / \mathrm{Al}$ ratio. The surface morphology of geopolymer composites became much more compact and smoothly when $N$ increased from 1.75 to 2 . When $N=1.75$, the viscosity of geopolymer slurry was relatively low, which favored the escape of the water in the initial stage of curing process, which can be explained the pore in the samples surface (Fig. 2c). Meanwhile, more surface water and pore water will loss in the curing process due to the loose microstructure. However, a geopolymer slurry with a moderate viscosity of was obtained when the $N=2$ compared with that of $1.75[22,23]$. Therefore, more uniform and compact microstructure was observed in the samples surface (Fig. 2b). When $N$ came to 2.25 , there were significant difference with $N=1.75$ or 2 . After $3 \mathrm{~d}$ curing, the geopolymer gel has not completely solidified, which was attributed to the presence of massive potassium silicate [24]. There were many cracks in the samples surface with $N=2.25$, which may be caused by the extrusion in the demoulding process. 


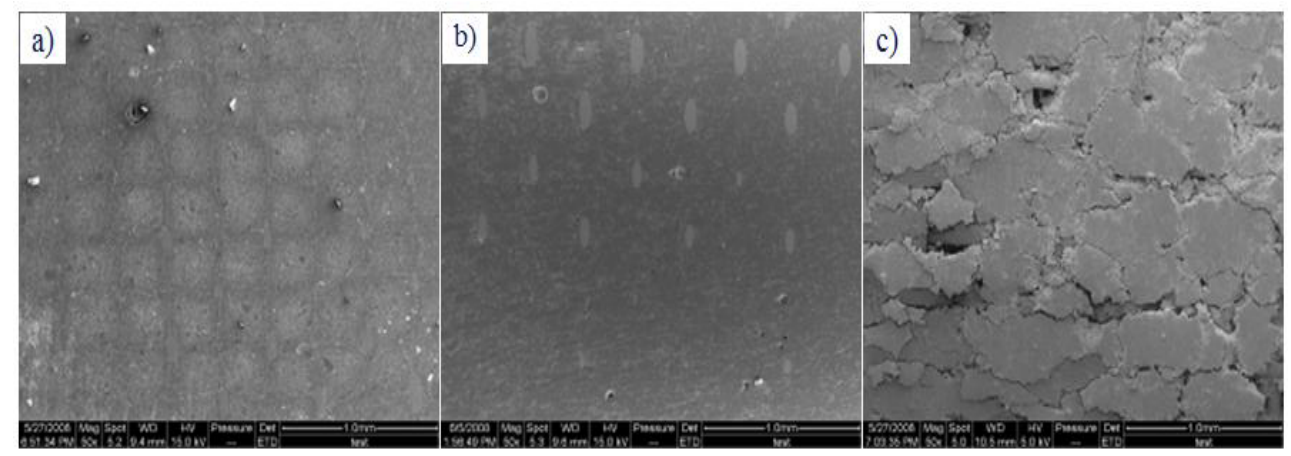

Fig. 2. Surface morphologies of geopolymer composites with different $\mathrm{Si} / \mathrm{Al}$ ratio, a) 1.75, b) 2 and c) 2.25

\subsection{Mechanical properties}

The $\mathrm{Si} / \mathrm{Al}$ ratio has a great influence on the mechanical properties of the resulting geopolymer composites, as shown in Fig. 3. With the increase in $\mathrm{Si} / \mathrm{Al}$ ratio, flexural strength, elasticity modulus, compressive strength and work of fracture of the composites showed similar trends, i.e., increasing first, reaching the highest value at $N=2$, and then decreasing. Take flexural strength for example (Fig .4): it increased from 96.3 MPa for composites with $N=1.75$ to the highest of $15.8 \mathrm{MPa}$ for composites with $N=2$. And almost all the mechanical properties reached the peak value when $N=2$. However, there was a significant declined in performance when $N=2.25$. As shown in Fig. 4 d, a mass of geopolymer matrix flaked away. The surface of stainless steel mesh was still smooth and no corrosion in the alkaline environment [21]. This might result from the weak interfacial strength between stainless steel mesh and geopolymer matrix [25]. In addition, microscopic defects such as interfacial gaps or the cracks in the surface also caused the loss of mechanical properties of geopolymer composites [26].

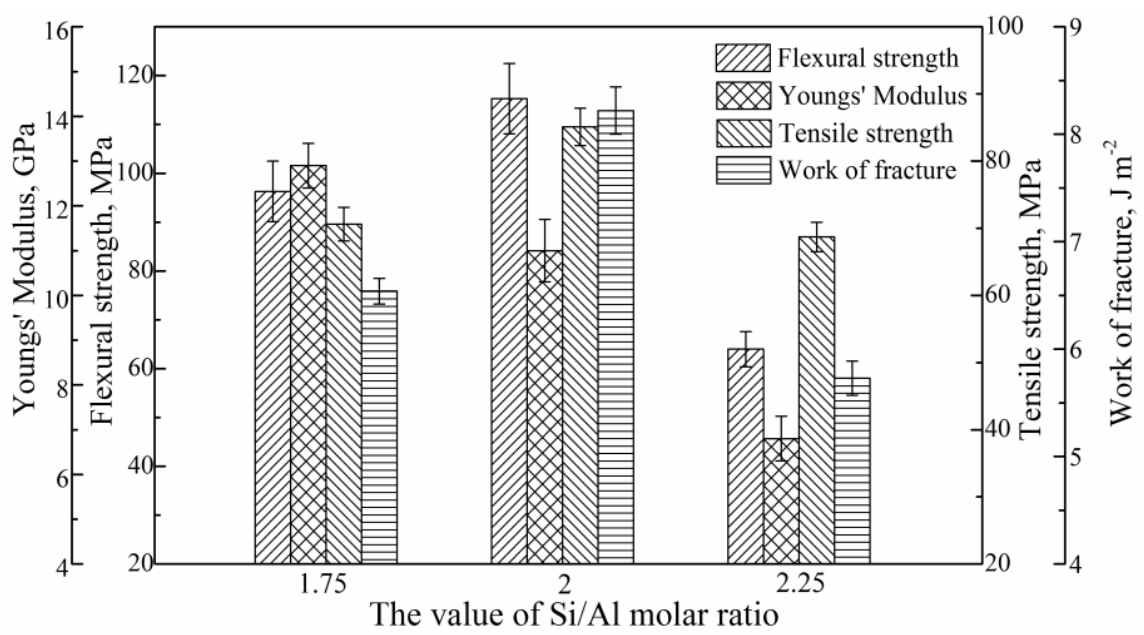

Fig. 3. Mechanical properties of geopolymer composites with different Si/Al ratio, a) 1.75, b) 2 and c) 2.25 . 

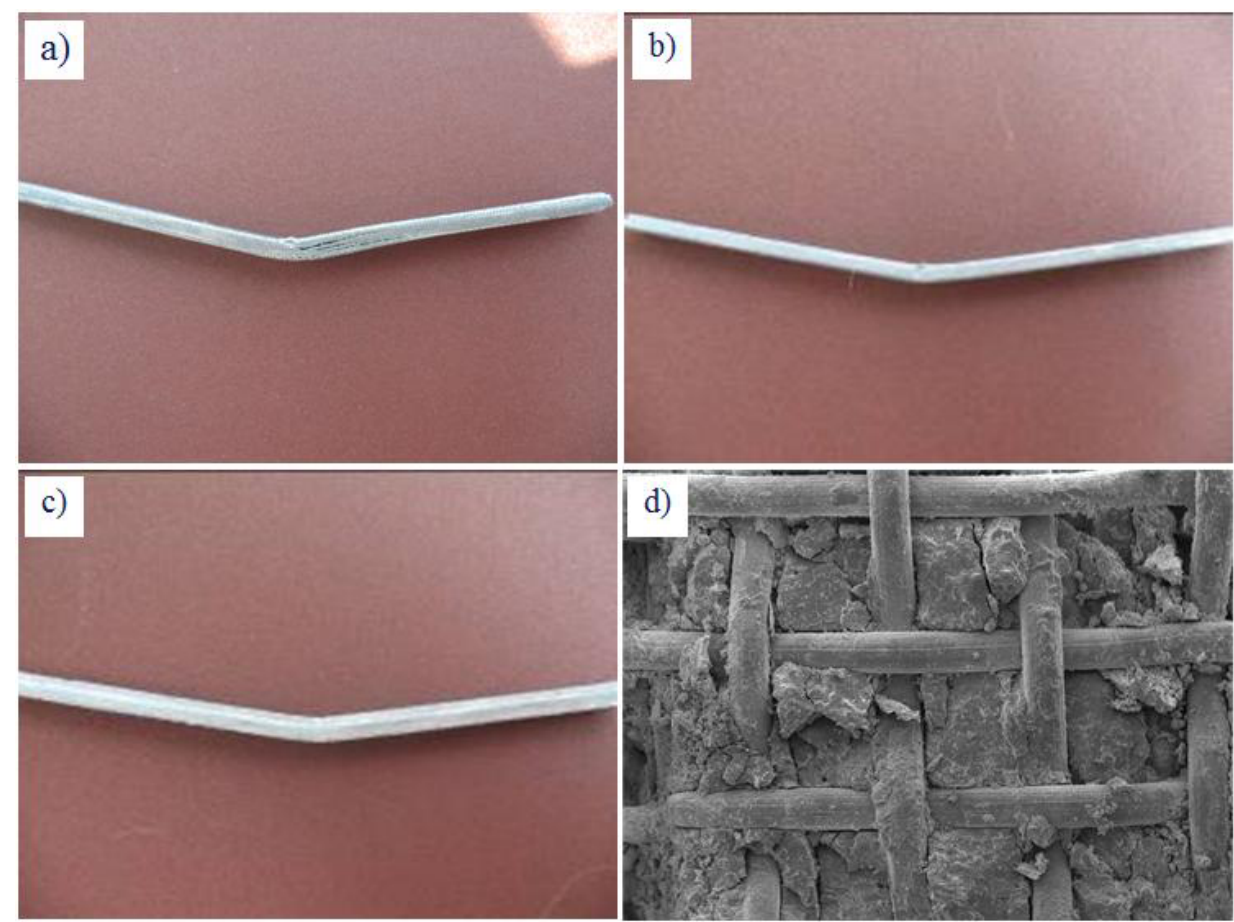

Fig. 4. The samples after three-point bending tests, a) 1.75 , b) 2 , c) 2.25 and d) the surface morphology with $N=2.25$.

\subsection{Fracture behavior}

Fig. 5. shows the load-displacement curves of geopolymer composites with different Si/Al molar ratio. Unlike $N=2.25$, the samples with $N=1.75$ or 2 showed a non-linear elastic increase of load before reaching the maximum load values. Then, the load decreased slowly with the displacement. The reason may be attributed to the bridging and sliding after debonding and pulling-out of the stainless steel mesh from the weak geopolymer matrix [27]. Meanwhile, the presence of chromium powder also was beneficial to enhancement of composites' toughness. However, the samples with $N=2.25$ displayed a fracture behavior as similar with metal materials, which indicated that there was little interfacial strength between stainless steel mesh and geopolymer matrix. The change of work of fracture also suggested the optimum $\mathrm{Si} / \mathrm{Al}$ ratio should be 2 . 


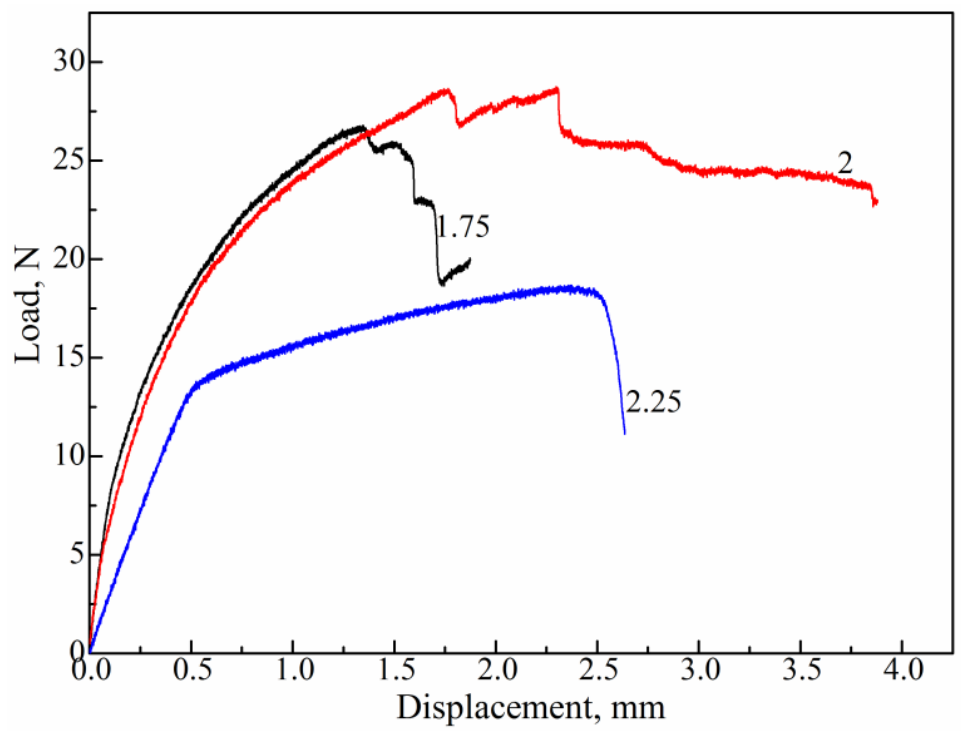

Fig. 5. Fracture behavior of geopolymer composites with different $\mathrm{Si} / \mathrm{Al}$ ratio.

\section{Summary}

In this paper, the effect of $\mathrm{Si} / \mathrm{Al}$ molar ratio on the performance of stainless steel mesh/Cr reinforced geopolymer composites was investigated. The results indicated that $\mathrm{Si} / \mathrm{Al}$ molar ratio had a significant impact on the final microstructure and mechanical properties of resulting geopolymer composites. The microstructure of geopolymer became more compact when $\mathrm{Si} / \mathrm{Al}$ increased from 1.75 to 2 , and the corresponding mechanical properties also reached the peak value. However, when $\mathrm{Si} / \mathrm{Al}$ came to 2.25 , the mechanical properties of composites declined. The results of fracture behavior suggested that the samples with $N=$ 2.25 displayed a fracture behavior as similar with metal materials, which different with $N=$ 1.75 and 2. The reason can be ascribed to different interfacial strength between reinforcements and geopolymer matrix, and composites with $N=2$ has an optimum interfacial strength compared with $N=1.75$ and 2.25 .

This work was supported by the Fundamental Research Funds for the Central Universities (Grant no. HITNSRIF20165), and the National Natural Science Foundation of China (NSFC, Nos. 51372048, 51502052, 51321061 and 51225203).

\section{References}

1. K.H. Yang, J.K. Song, K.I. Song, J. Clean. Prod., 39, 265 (2013)

2. P. Hlavacek, V. Smilauer, F. Skvara, L. Kopecky, R. Sulc, J. Eur. Ceram. Soc., 35, 703 (2015)

3. A. Favier, G. Habert, J.B.D.E.d. Lacaillerie, N. Roussel, Cem. Concr. Res., 48, 9 (2013)

4. Z. Zhang, X. Yao, H. Zhu, Appl. Clay Sci., 49, 1 (2010)

5. V.F.F. Barbosa, K.J.D. Mackenzie, Mater. Res. Bull., 38, 319 (2003)

6. F. Slaty, H. Khoury, H. Rahier, J. Wastiels, Appl. Clay Sci., 104, 229 (2015)

7. W.D.A. Rickard, L. Vickers, A.V. Riessen, Appl. Clay Sci., 73, 71 (2013)

8. J. Davidovits, J. Therm. Anal., 37, 1633 (1991)

9. J. Davidovits, J. Therm. Anal., 35, 429 (1989) 
10. K. Komnitsas, D. Zaharaki, A. Vlachou, G. Bartzas, M. Galetakis, Adv. Powder Technol, 26, 368 (2015)

11. B.H. Mo, Z. He, X.M. Cui, Y. He, S.Y. Gong, Appl. Clay Sci., 99, 144 (2014)

12. J.L. Provis, J.S.J.V. Deventer, Geopolymers : Structures, Processing, Properties and Industrial Applications (Elsevier, United Kingdom, 2009)

13. X. Yao, Z. Zhang, H. Zhu, Y. Chen, Thermochim Acta, 493, 49 (2009)

14. L. Weng, K.S. Crentsil, J. Mater. Sci., 42, 2997 (2007)

15. P.S. Singh, M. Trigg, I. Burgar, T. Bastow, Mater. Sci. Eng. A Struct., 396, 392 (2005)

16. M.R. Rowles, B.H. O'Connor, J. Am. Ceram. Soc., 92, 2354 (2009)

17. I. Ozer, S.S. Uzun, Ceram. Inter., 41, 10192 (2015)

18. K. Komnitsas, D. Zaharaki, V. Perdikatsis, J. Mater. Sci., 42, 3073 (2006)

19. G. Gorhan, G. Kurklu, Compos. Part B-Eng., 58, 371 (2014)

20. P. Duxson, A.F. Jimenez, J.L. Provis, G.C. Lukey, A. Palomo, J.S.J.V. Deventer, J. Mater. Sci., 42, 2917 (2006)

21. P.G. Allison, C.A. Weiss, J.R.D. Moser, A.J. Diaz, O.G. Rivera, S.S. Holton, Compos. Part B-Eng., 78, $131(2015)$

22. P. Duxson, G.C. Lukey, J.S.J.V. Deventer, J. Non Cryst Solids, 352, 5541 (2006)

23. P. Duxson, G.C. Lukey, J.S.J.V. Deventer, Langmuir, 22, 8750 (2006)

24. A. Hajimohammadi, J.L. Provis, J.S.J.V. Deventer, Cem. Concr. Res., 41, 210 (2011)

25. A. Castel, S.J. Foster, Cem. Concr. Res., 72, 48 (2015)

26. J. Yuan, P. He, D. Jia, S. Yan, D. Cai, L. Xu, Z. Yang, X. Duan, S. Wang, Y. Zhou, Ceram. Inter., 42, 5345 (2016)

27. Q. Zhao, B. Nair, T. Rahimian, P. Balaguru, J. Mater. Sci., 42, 3131 (2007) 